\title{
Effect of Hot Deformation Temperature on Texture Formation Regularity of CGO Silicon Steel under High Deformation Rate
}

\author{
Zhi-chao Li, ${ }^{1}$ Ning Dang, ${ }^{2}$ and Zhen-li $\mathrm{Mi}^{2}$ \\ ${ }^{1}$ Collaborative Innovation Center of Steel Technology, University of Science and Technology, Beijing 100083, China \\ ${ }^{2}$ Institute of Engineering Technology, University of Science and Technology, Beijing 100083, China \\ Correspondence should be addressed to Zhi-chao Li; lizhichao1225@163.com
}

Received 21 April 2016; Revised 30 June 2016; Accepted 25 July 2016

Academic Editor: Jingwei Zhao

Copyright (c) 2016 Zhi-chao Li et al. This is an open access article distributed under the Creative Commons Attribution License, which permits unrestricted use, distribution, and reproduction in any medium, provided the original work is properly cited.

\begin{abstract}
The influence of hot deformation temperature on microstructure and texture of CGO silicon steel under the condition of a high deformation rate $\left(100 \mathrm{~s}^{-1}\right)$ was studied by SEM and EBSD techniques. The results indicate that the typical microstructures at room temperature consist of ferrite and pearlite under different hot deformation temperatures. The higher deformation temperature is beneficial to obtain a more uniform recrystallization microstructure and lower pearlite content. Cubic texture $\{100\}\langle 001\rangle$ and rotated cubic texture $\{100\}\langle 011\rangle$ are dominant texture components in the tested steels, and $\{111\}\langle 112\rangle$ texture in $\gamma$ fiber is also strong, the intensity of which is higher than that of $\{111\}\langle 110\rangle$ texture. Goss texture $\{110\}\langle 001\rangle$ is weak. With the rising of the hot deformation temperature, $\{100\}\langle 011\rangle$ texture decreases firstly and then increases at $1100^{\circ} \mathrm{C}$. When the hot deformation temperature raises from $800^{\circ} \mathrm{C}$ to $900^{\circ} \mathrm{C},\{111\}\langle 112\rangle$ texture shows an increasing trend, while $\{111\}\langle 110\rangle$ texture content is stable. When the temperature further increases to $1100^{\circ} \mathrm{C}$ and $1150^{\circ} \mathrm{C},\{111\}\langle 112\rangle$ and $\{111\}\langle 110\rangle$ textures are slightly weakened.
\end{abstract}

\section{Introduction}

Grain-oriented silicon steel is an important soft magnetic material which is widely applied in electronic and electric power industry and mainly used for the manufacture of transformers and so forth $[1,2]$. The metallurgical factors which affect the magnetic properties include the steel composition, microstructure, crystallographic texture, grain size, and internal stress, of which microstructure and texture are important influencing factors [3]. Due to the obvious inheritance of the textures [4] during manufacturing, the hot rolling textures have significant effect [5] on the texture evolution during the following process of grain-oriented silicon steel. The research on the origin and evolution of textures is beneficial for the optimization of texture control in the production processes. The deformation rate applied to grain-oriented silicon steel in actual hot rolling process is relatively high. Despite numerous researches on the effect of the hot rolling temperature on the microstructure and texture of grain-oriented silicon steel at present, the research under the condition of a high strain rate is not much. Liu et al.
[6] studied hot rolling texture distribution at different temperatures using a thermal simulator under low deformation rate condition. In this study, the texture evolution during hot rolling process was simulated by uniaxial compression. The results show that gamma textures which have strong inheritance play an important role in the subsequent process and improve the concentration of textures after secondary recrystallization. Zhang et al. [7] studied hot rolling textures of $3.2 \% \mathrm{Si}$ grain-oriented silicon steel and the inheritance of textures between hot rolling and subsequent processes, this research focused on microstructure, and texture evolution of the static recrystallization occurred in the process of annealing after the deformation of CGO silicon steel. The results show that there is no obvious heterogeneity along the thickness direction after primary recrystallization, and $\{111\}\langle 110\rangle$ texture is the strongest texture component, and there is a certain intensity of the Goss texture. The texture formation mechanism is different between dynamic recrystallization and static recrystallization. The texture is definitely different between hot compression and hot rolling which is used industrially, and Zhichao et al. [8,9] have done some 
researches on the formation and evolution of textures in hot rolling process, but the thermal compression process is not involved in the same deformation conditions, and this process has significant impact on the texture evolution during hot deformation. The rough rolling of CGO steel usually has a high rolling speed which is closed to $100 \mathrm{~s}^{-1}$, so that the texture evolution during this process is difficult to analyze, and limited work is available in the literature on this impact. It is therefore important to summarize the texture evolution law under the large deformation rate with different temperatures. This paper investigate the effect of hot deformation temperature on the microstructure and texture of grain-oriented silicon steel under the condition of a high deformation rate, which provides reference to the texture control during the manufacturing process of grain-oriented silicon steel.

\section{Experimental Materials and Methods}

Experimental materials are cut from an ingot which has a chemical composition of $0.065 \% \mathrm{C}, 2.95 \% \mathrm{Si}, 0.15 \% \mathrm{Mn}$, and $0.027 \% \mathrm{~S}$ and processed into cylinder specimens. The experimental process is illustrated in Figure 1. The specimens were heated to $1300^{\circ} \mathrm{C}$ at $10^{\circ} \mathrm{C} / \mathrm{s}$, held for $3 \mathrm{~min}$, and then cooled, respectively, to $800,850,900,1100$, and $1150^{\circ} \mathrm{C}$ at $4^{\circ} \mathrm{C} / \mathrm{s}$ and conducted uniaxial compression with the same deformation rate of $100 \mathrm{~s}^{-1}$. Test samples were cut along the axis of compression specimen and their microstructures in center layer were analyzed by field emission scanning electron microscopy (SEM) after mechanical polishing and etching. The orientation distributions were measured by electron back-scattered diffraction (EBSD) attached to Zeiss ultra 55 SEM. The experimental data were analyzed by Channel 5 software and the contents of typical textures were obtained.

\section{Results and Discussion}

3.1. Microstructures of Experimental Steels. The phase diagrams of the experimental steels are calculated using ThermoCalc software. Figure 2(a) presents the effect of carbon content on the microstructure of the steel. Figure 2(b) presents the dependence of the relative qualities of austenite, ferrite, cementite, and so forth on the temperature. It can be seen from Figure 2 that when the $\mathrm{C}$ content is in a range of $0.04-0.78 \%$, the high temperature microstructure at $1200^{\circ} \mathrm{C}$ is single-phase austenite. During the cooling process, the proeutectoid ferrite occurs firstly, and two-phase range of austenite and ferrite exists. With the formation of ferrite, the concentration of carbon in ferrite is very low and reduces with the decreasing of temperature, and $\mathrm{C}$ atoms diffuse to the surrounding austenite. This process is accompanied with the decreasing of temperature and the formation of ferrite continuously. At the five experimental temperatures between 800 and $1100^{\circ} \mathrm{C}$, deformation specimens are at the "ferrite + austenite" two-phase range, the austenite has the highest relative content at $1180^{\circ} \mathrm{C}$, and the content will reduce with the decreasing of temperature.

Figures 3(a)-3(e) present the microstructures of the experimental steels at different deformation temperatures

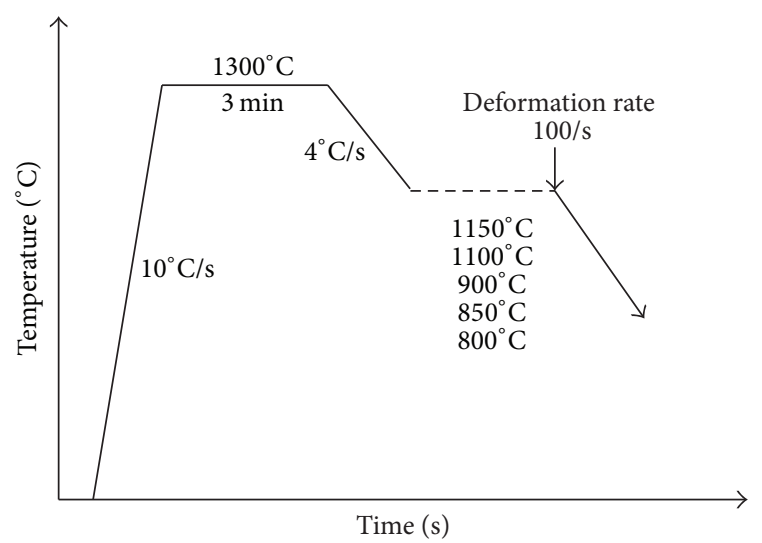

FiguRE 1: Processing route of thermal simulation experiment.

under a high deformation rate. Figure 3(f) illustrates the average grain size of different specimens. Typical microstructures consist of ferrite and pearlite, and the microstructure morphologies of the samples show significant differences under various deformation temperatures. The recrystallization grains of the specimens deformed at 850 and $900^{\circ} \mathrm{C}$ are coarse, and their grain size distributions are inhomogeneous. At the deformation temperatures of $1100^{\circ} \mathrm{C}$ and $1150^{\circ} \mathrm{C}$, the recrystallization degrees of part grains are low and the content of pearlite is higher. With the increases of deformation temperature, the recrystallization grain size decreases gradually and the grain size distribution is more uniform. It can be obtained from Figure 2(b) that, with the increasing of deformation temperature, the austenite proportion becomes larger and the supersaturation of $\mathrm{C}$ in austenite decreases. The deformed austenite recrystallizes sufficiently, leading to fine and uniform size of deformed austenite. At the same time, crystal distortion is small and is not conducive for the diffusion of the $\mathrm{C}$ atoms from inside of grains to grain boundaries where pearlite nucleates, which lead to the difficulty of alternative growth of pearlite lamellae. The pearlite layer is thinner after high temperature deformation and pearlite area is smaller. In addition, due to the increasing of deformed austenite, pearlite distribution becomes more uniform after phase transformation. During $800 \sim 900^{\circ} \mathrm{C}$, recrystallization degree is weak, distortion of deformed austenite is large, and it is conductive to the diffusion of $\mathrm{C}$ atoms. Coarse pearlite is formed after phase transformation and distributed intensively because of the decreasing of deformed austenite. During rolling in two-phase range of ferrite and austenite, the degree of recrystallization is lower at low temperature. At a higher deformation temperature, ferrite and austenite are compressed and form dislocation-substructure inside of the grains [9]. The higher temperature provides driving force for the grain growth, which leads to the recrystallization and the growth of ferrite grains in a wide range. When the deformation temperature is low, austenite grains are elongated without recrystallization and dislocation-substructures accumulated within grains, which become nucleation sites of phase transformation. The elongated austenite grain boundaries restrict the growth of newly formed microstructures. 


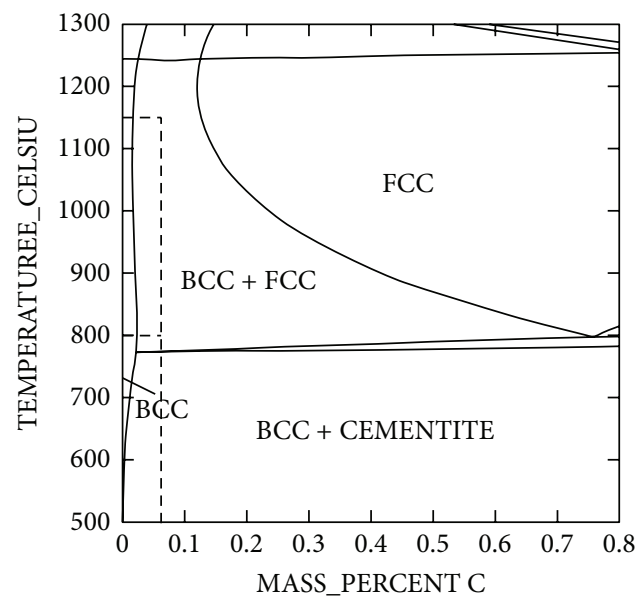

(a)

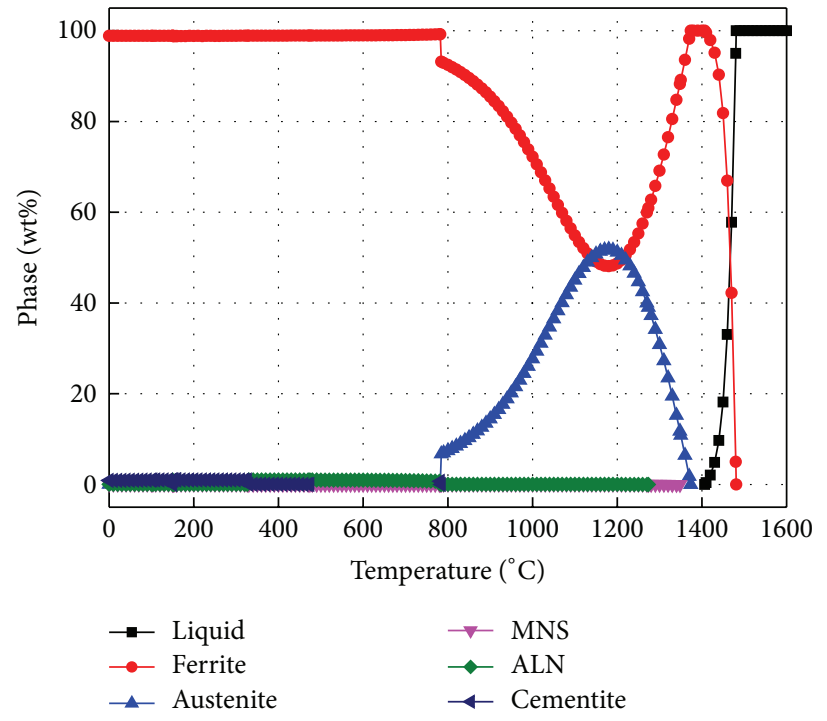

(b)

Figure 2: Thermodynamic calculated phase diagram. (a) Fe-C phase diagram; (b) the relative amount of different phases change with temperature.

So it can be observed from Figure 3(b) that the grain bands did not grow up sufficiently between the gaps of larger size grains. During the cooling, ferrite and cementite will generate inside of austenite and the newly formed ferrite has small size because of the limitation of austenite grain boundaries. At lower deformation temperature, there are long strip recovery microstructures which remain in the matrix, such as Figures 3(b) and 3(c).

3.2. Textures of Experimental Steels. The initial textures before high temperature deformation are distributed randomly because the experimental materials are cut from forged CGO silicon steel. The orientation image maps of the experimental steels with high deformation rate at different deformation temperatures were shown in Figure 4 and the area fractions of different textures were listed in Table 1 and Figure 5. Various colors represent grains with different orientation, Goss $\{110\}\langle 001\rangle$ oriented grains is red, $\{111\}\langle 121\rangle$ oriented grains is yellow, $\{111\}\langle 100\rangle$ oriented grains is blue, cubic oriented grains is brown, rotated cube $\{100\}\langle 011\rangle$ oriented grains is green, brass-type $\{110\}\langle 112\rangle$ oriented grains is purple, and copper-type $\{112\}\langle 111\rangle$ oriented grains is blue.

Cubic texture $\{100\}\langle 001\rangle$, rotated cube texture $\{100\}\langle 011\rangle$, gamma fiber textures including $\{111\}\langle 112\rangle$ and $\{111\}\langle 110\rangle$ textures, Goss texture $\{110\}\langle 001\rangle$, coppertype texture $\{112\}\langle 111\rangle$, and brass-type $\{110\}\langle 112\rangle$ texture are important texture components in grain-oriented silicon steel and their existence in hot rolled plate will influence the subsequent texture development [11-13].

As can be seen in Table 1, in general, cube texture $\{100\}\langle 001\rangle$ and rotated cube texture $\{100\}\langle 011\rangle$ are dominant texture components at different hot deformation temperatures. In addition, the contents of $\{111\}\langle 112\rangle$ in $\gamma$ fiber and copper-type $\{112\}\langle 111\rangle$ texture are also higher. Goss
TABLE 1: Texture contents of samples under different hot deformation temperatures in tested steels (\%).

\begin{tabular}{lccccc}
\hline $\begin{array}{l}\text { Hot deforming } \\
\text { temperatures } /{ }^{\circ} \mathrm{C}\end{array}$ & 800 & 850 & 900 & 1100 & 1150 \\
\hline$\{100\}\langle 001\rangle$ & 19.4 & 7.8 & 13.4 & 13.2 & 17.9 \\
$\{100\}\langle 011\rangle$ & 17.2 & 15.4 & 4.8 & 11.0 & 22.9 \\
$\{110\}\langle 001\rangle$ & 2.2 & 2.0 & 8.6 & 2.9 & 1.3 \\
$\{110\}\langle 112\rangle$ & 4.8 & 5.3 & 5.2 & 7.7 & 2.9 \\
$\{111\}\langle 110\rangle$ & 9.5 & 6.5 & 9.9 & 7.5 & 6.7 \\
$\{111\}\langle 112\rangle$ & 8.1 & 8.5 & 11.2 & 8.0 & 7.5 \\
$\{112\}\langle 111\rangle$ & 8.3 & 16.6 & 8.5 & 5.9 & 7.5 \\
\hline
\end{tabular}

texture $\{110\}\langle 001\rangle$ is weak and its content is low. The contents of texture components will change at various deformation temperatures. For instance, with the rising of hot deformation temperature, the content of rotated cube texture $\{100\}\langle 011\rangle$ decreases first and then increases further. The content of $\{111\}\langle 112\rangle$ texture and copper-type texture $\{112\}\langle 111\rangle$ increase first and then reduce.

From Table 1 and Figure 6 it can be seen that the content of Goss texture $\{110\}\langle 001\rangle$ is low at most of the hot deformation temperatures. Goss texture of hot rolled plate originates from the broken columnar crystal with $\langle 100\rangle$ direction in casting billet [14-16]. During the hot deformation process, Goss texture formed by shear strain will transit to other orientations under high deformation rate because of the migration of the high angle grain boundaries. Goss oriented grains will transform to brass-type texture $\{110\}\langle 112\rangle$ and copper-type $\{112\}\langle 111\rangle$ texture because of the orientation conversion relationship. The intensity of copper-type texture $\{112\}\langle 111\rangle$ is higher than the Goss texture $\{110\}\langle 001\rangle$ which can be seen in Table 1. During the cold rolling, Goss 


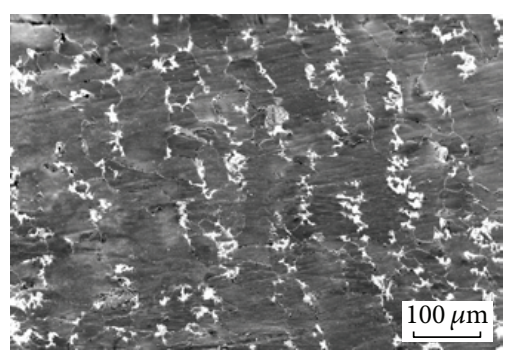

(a)

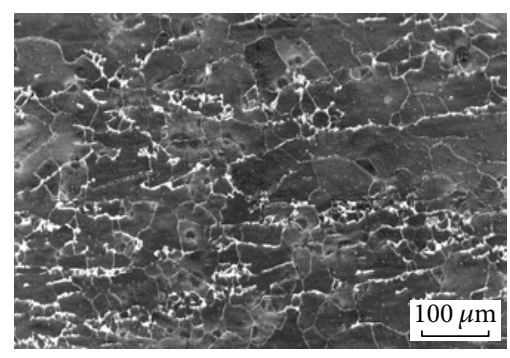

(b)

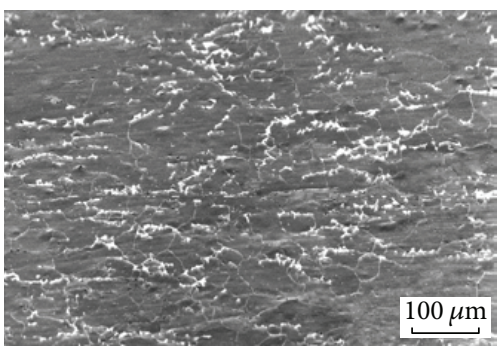

(c)

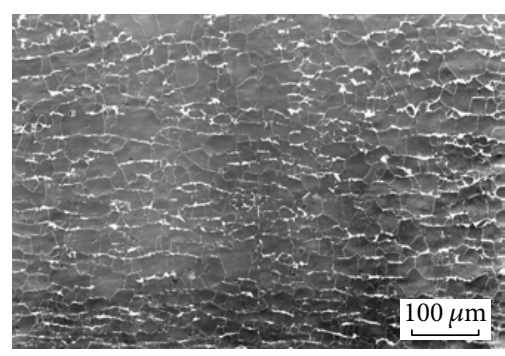

(d)

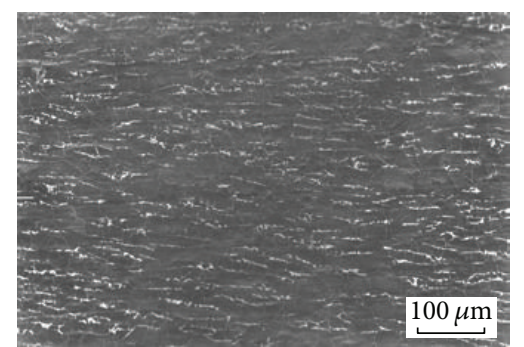

(e)

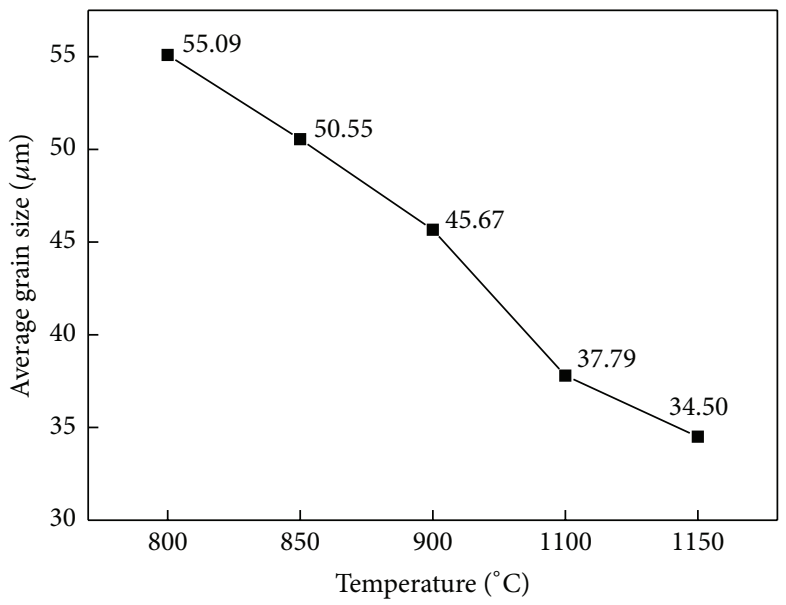

(f)

Figure 3: Microstructure of samples under different hot deformation temperatures. (a) $800^{\circ} \mathrm{C}$; (b) $850^{\circ} \mathrm{C}$; (c) $900^{\circ} \mathrm{C}$; (d) $1100^{\circ} \mathrm{C}$; (e) $1150^{\circ} \mathrm{C}$; (f) average grain size variation.

oriented grains descend from the broken columnar grains with $\langle 100\rangle$ direction of casting billet and are prone to transit to $\{223\}\langle 110\rangle$ texture along certain path. However, it is difficult to obtain the final $\{223\}\langle 110\rangle$ texture because of the restriction of certain conditions. In brief, the content of Goss texture $\{110\}\langle 001\rangle$ is low in the steels which experienced thermal deformation.

Rotated cube texture $\{100\}\langle 011\rangle$ is the common component in hot rolled plate. From Table 1 and Figure 5 it can be seen that, with the rising of deformation temperature, the content of $\{100\}\langle 011\rangle$ texture decreases first and then increases. The texture characteristics of single crystal under different rolling reductions indicate that when the rolling reduction was greater than $60 \%,\{211\}\langle 011\rangle$ and $\{100\}\langle 011\rangle$ texture components are enhanced because of $\{211\}\langle 111\rangle$ slip system during thermal deformation $[17,18]$, which explains the fact that the content of rotated cube texture $\{100\}\langle 110\rangle$ is high at all the deformation temperature. The rotated cube texture $\{100\}\langle 110\rangle$ is difficult to recrystallize [19] and should be eliminated in the subsequent process. The typical texture during austenite recrystallization is cubic texture. All steels with different deformation temperature therefore have a high proportion of $\{100\}\langle 001\rangle$ cubic texture. However, the cubic texture is an unfavorable component which is formed by the initial columnar crystal in grain-oriented silicon steel. Researches [10] indicated that, in the subsequent process, the repeated rolling and annealing can weaken the heredity of $\{100\}$ texture and decrease the $\{100\}\langle 001\rangle$ cubic texture.

As can be seen in Figure 4, for the grains with $\{111\}$ crystal plane, when the hot deformation temperature increased from $800^{\circ} \mathrm{C}$ to $900^{\circ} \mathrm{C},\{111\}\langle 112\rangle$ texture shows an increasing trend, while $\{111\}\langle 110\rangle$ texture is relatively stable. When 

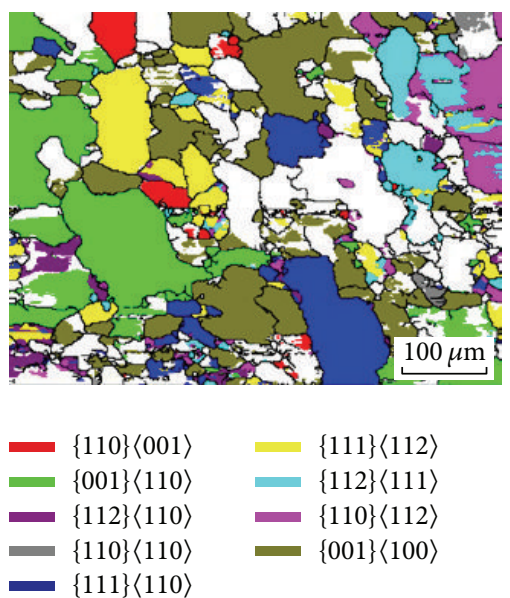

(a)
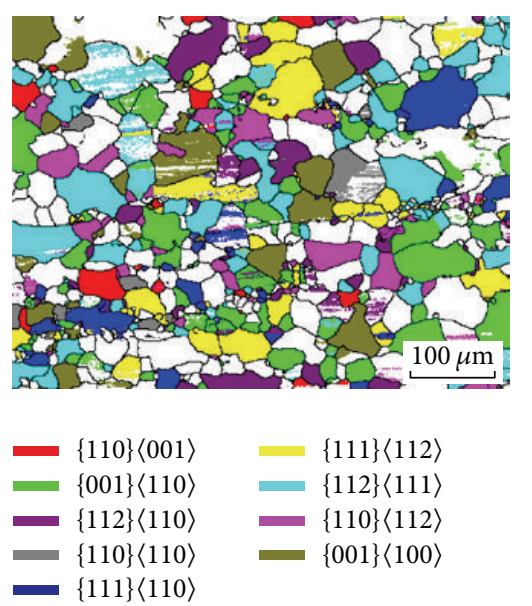

$\{111\}\langle 110\rangle$

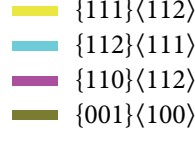

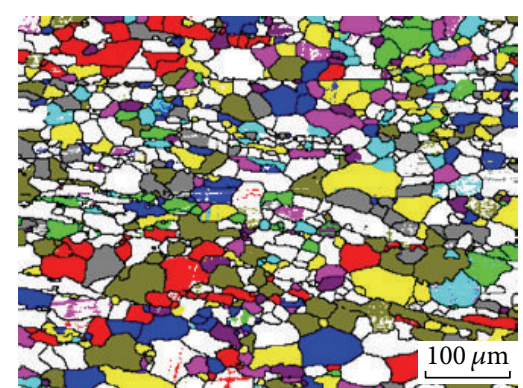

(b)

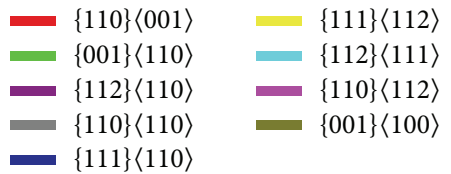

(c)
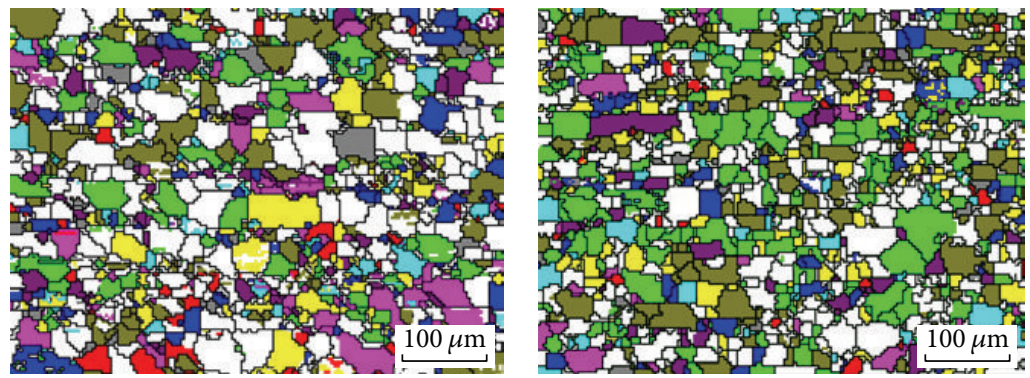

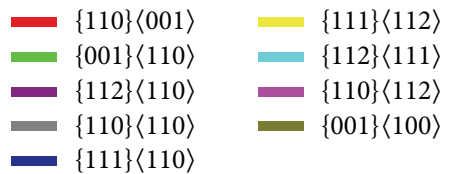

(d)

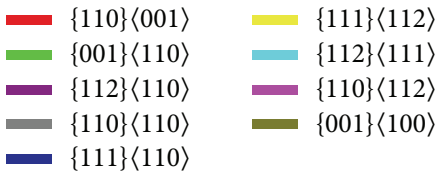

(e)

FIGURE 4: EBSD analysis of samples under different hot deformation temperatures. (a) $800^{\circ} \mathrm{C}$; (b) $850^{\circ} \mathrm{C}$; (c) $900^{\circ} \mathrm{C}$; (d) $1100^{\circ} \mathrm{C}$; (e) $1150^{\circ} \mathrm{C}$.

the hot deformation temperature was increased to $1100^{\circ} \mathrm{C}$ and even $1150^{\circ} \mathrm{C}$ further, $\{111\}\langle 112\rangle$ texture and $\{111\}\langle 110\rangle$ texture are slightly weakened. $\{111\}$ plane textures are the typical recrystallization texture, whose proportion in experimental steels is closely related to the recrystallization degree. $\{111\}$ plane textures provide nucleation sites for the abnormal growth of Goss grains during secondary recrystallization process $[1,12]$, which are important growth environment for Goss oriented grains $[20,21]$. In the recrystallization after deformation, the stored energies are different in various texture components, which are $\{001\}\langle 110\rangle,\{112\}\langle 110\rangle$, $\{111\}\langle 110\rangle$, and $\{111\}\langle 112\rangle$ in an order from strong to weak. $\{111\}\langle 110\rangle$ and $\{111\}\langle 112\rangle$ oriented grains can nucleate and grow preferentially due to higher stored energies. From Figure 4 it can be seen that $\{111\}\langle 110\rangle$ and $\{111\}\langle 112\rangle$ oriented grains present a higher degree of recrystallization. Because it is easier for $\{111\}\langle 112\rangle$ texture to form shear bands compared with $\{111\}\langle 110\rangle$ texture [22], $\{111\}\langle 112\rangle$ oriented grains are more likely to grow up. From Table 1 it can be seen that the intensity of $\{111\}\langle 112\rangle$ texture is stronger than $\{111\}\langle 100\rangle$ texture in multiple thermal deformation temperatures.
During the hot compression with high strain rate of CGO silicon steel, scattered $\alpha$ fiber texture merged into $\{100\}\langle 011\rangle$ texture and cube $\{100\}\langle 011\rangle$ texture was formed because of strong rotation of grains. Under high stain rate, cubic texture $\{100\}\langle 001\rangle$ keeps stable and takes a great proportion. Copper texture $\{112\}\langle 111\rangle$ and brass texture $\{110\}\langle 112\rangle$ are typical shear textures. Brass texture $\{110\}\langle 112\rangle$ is derived from shear layer which forms at the subsurface of the plate during hot rolling and is closely related to Goss texture $\{110\}\langle 001\rangle$. The formation of brass texture $\{110\}\langle 112\rangle$ is due to the inhibition of grain boundaries. The rotation of Goss oriented grains along TD direction is impeded so that the grains rotate along ND direction instead.

\section{Conclusions}

(1) The typical microstructures at room temperature of CGO silicon steel after hot deformation are ferrite and pearlite, and there are some differences in grain size distributions and morphologies. A high hot deformation temperature is benefit to obtain a more uniform recrystallized microstructure and lower pearlite 


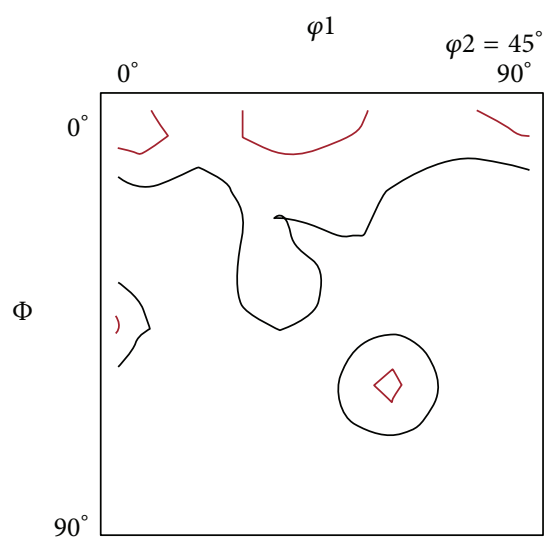

(a)

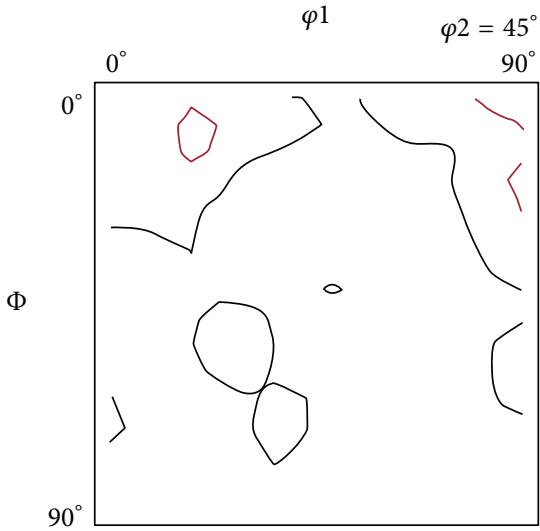

(b)

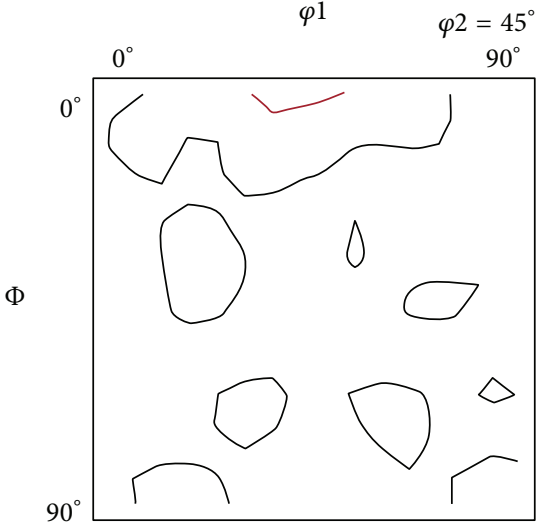

(c)

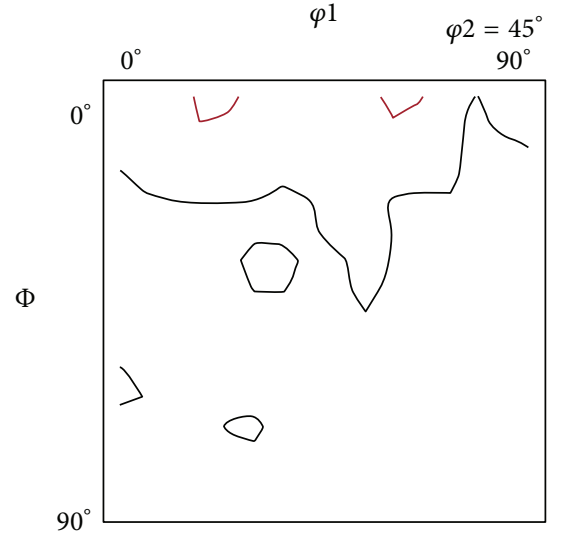

(d)

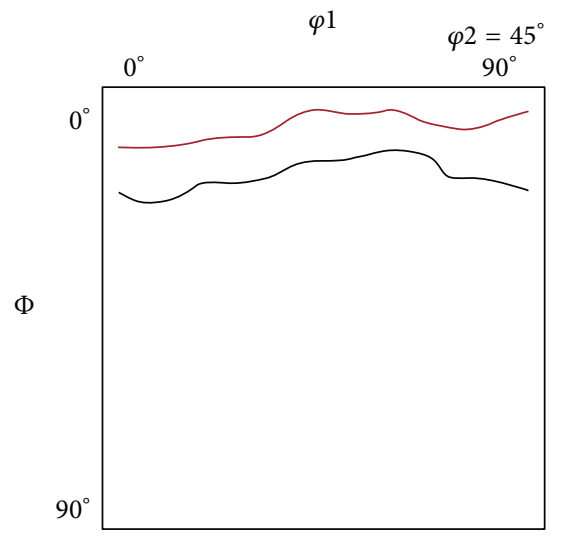

(e)

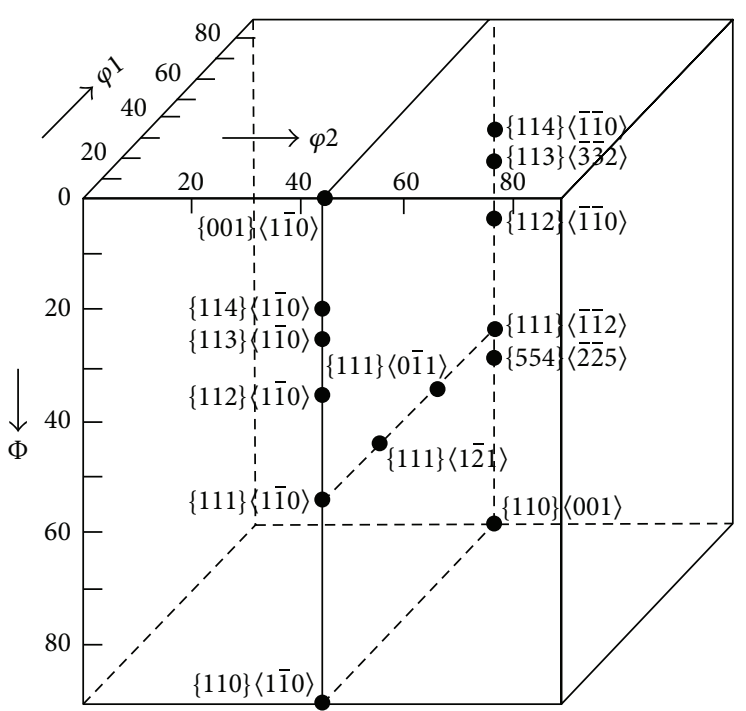

(f)

Figure 5: ODF analysis of samples under different hot deformation temperatures. (a) $800^{\circ} \mathrm{C}$; (b) $850^{\circ} \mathrm{C}$; (c) $900^{\circ} \mathrm{C}$; (d) $1100^{\circ} \mathrm{C}$; (e) $1150^{\circ} \mathrm{C}$; (f) distribution of main orientations in Euler space for silicon steel [10].

content. A low deformation temperature leads to higher pearlite content and partial recrystallization.

(2) The cubic texture $\{100\}\langle 001\rangle$ and rotated cubic texture $\{100\}\langle 011\rangle$ are dominant texture components in the tested steels after hot deformation. The $\{111\}\langle 112\rangle$ texture in $\gamma$ fiber is also strong, and its strength is higher than that of $\{111\}\langle 110\rangle$ texture, whereas the content of Goss texture $\{110\}\langle 001\rangle$ is very low.

(3) With the rising of deformation temperature, the content of the rotated cube $\{100\}\langle 011\rangle$ texture decreases 


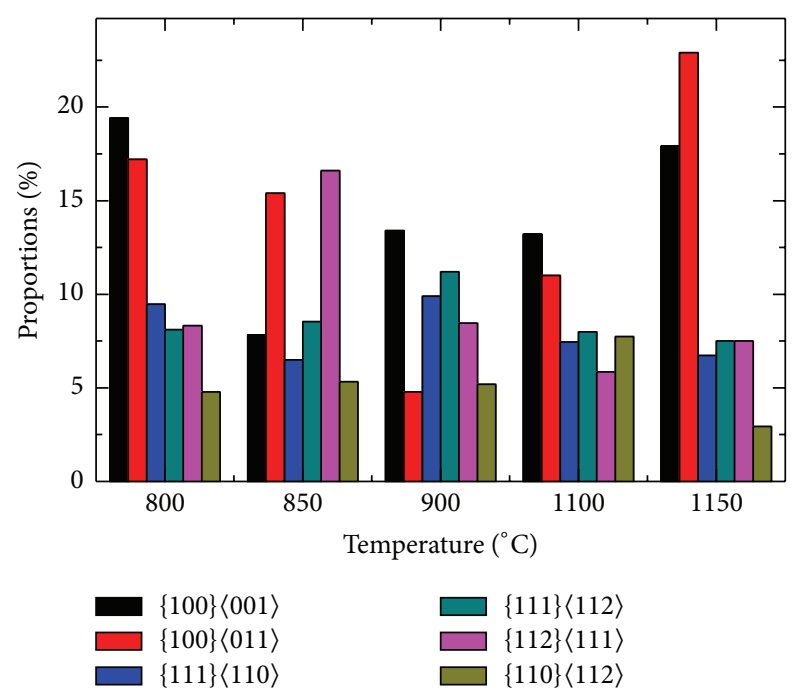

FIGURE 6: Texture contents of samples under different hot deformation temperatures in tested steel.

first and then increases when the deformation temperature further achieved to $1100^{\circ} \mathrm{C}$; when the deformation temperature raises from $800^{\circ} \mathrm{C}$ to $900^{\circ} \mathrm{C}$, $\{111\}\langle 112\rangle$ texture shows an increasing trend, and $\{111\}\langle 110\rangle$ texture is more stable. When the hot deformation temperature continues to increase to $1100^{\circ} \mathrm{C}$ and $1150^{\circ} \mathrm{C},\{111\}\langle 112\rangle$ texture and $\{111\}\langle 110\rangle$ texture are slightly weakened.

\section{Competing Interests}

The authors declare that they have no competing interests.

\section{Acknowledgments}

This works is supported by Fundamental Research Funds for the Central Universities (TP-A3), no. FRF-TP-15-063A3.

\section{References}

[1] J. Y. Park, K. S. Han, J. S. Woo, S. K. Chang, N. Rajmohan, and J. A. Szpunar, "Influence of primary annealing condition on texture development in grain oriented electrical steels," Acta Materialia, vol. 50, no. 7, pp. 1825-1834, 2002.

[2] Y. Hayakawa and M. Kurosawa, "Orientation relationship between primary and secondary recrystallized texture in electrical steel," Acta Materialia, vol. 50, no. 18, pp. 4527-4534, 2002.

[3] T. Yonamine and F. J. G. Landgraf, "Correlation between magnetic properties and crystallographic texture of silicon steel," Journal of Magnetism and Magnetic Materials, vol. 272276, supplement 1, pp. E565-E566, 2004.

[4] C. Gheorghies and A. Doniga, "Evolution of texture in grain oriented silicon steels," Journal of Iron and Steel Research International, vol. 16, no. 4, pp. 78-83, 2009.

[5] L. Cheng, N. Zhang, P. Yang et al., "Retaining $\{100\}$ texture from initial columnar grains in electrical steels," Scripta Materialia, vol. 67, no. 11, pp. 899-902, 2012.
[6] L.-L. Liu, Y.-L. Feng, and B. Hou, "Microstructure and texture in hot rolling strip of low temperature oriented silicon steel," Hot Working Technology, vol. 43, no. 12, pp. 99-102, 2014.

[7] Z.-Z. Zhang, W. Ren, and J.-F. Fang, "Texture evolution of primary recrystallization and deformation of grain-oriented electrical steel with low temperature slab reheating," Iron and Steel, vol. 46, no. 8, pp. 83-88, 2011.

[8] L. I. Zhichao, S. U. N. Qiang, M. Zhenli, and L. Ruimin, "Lin Ruimin. Effect of cooling rate on annealing textures in hot rolled 1. 35\%Si non-oriented electrical steel," Transactions of Materials and Heat Treatment, vol. 37, no. 2, pp. 104-109, 2016.

[9] Q. Sun, L. Zhichao, M. Zhenli, and l. Ruimin, "Effect of chemical composition on recrystallized microstructure and texture of hot rolled non-oriented electrical steel," Transactions of Materials and Heat Treatment, vol. 37, no. 4, pp. 82-87, 2016.

[10] S. Wang, Influence of Rolling Direction on the Texture Evolution of Grain-Oriented Silicon Steel, University of Science and Technology, Liaoning, Anshan, China, 2013.

[11] N. Bernier, E. Leunis, C. Furtado, T. Van De Putte, and G. Ban, "EBSD study of angular deviations from the Goss component in grain-oriented electrical steels," Micron, vol. 54-55, pp. 4351, 2013.

[12] Y.-Y. Shao, P. Yang, Y.-J. Fu, and W.-M. Mao, “Texture evolution of columnar grains in electrical steel during hot rolling," Journal of Iron and Steel Research International, vol. 20, no. 10, pp. 99106, 2013.

[13] L. Xie, P. Yang, N. Zhang et al., "Formation of $\{100\}$ textured columnar grain structure in a non-oriented electrical steel by phase transformation," Journal of Magnetism and Magnetic Materials, vol. 356, pp. 1-4, 2014.

[14] Y.-Y. Shao, P. Yang, and W.-M. Mao, "Evolution of orientations and their influence on precipitation during hot compression of columnar-grained electrical steel," Journal of Materials Engineering, vol. 10, pp. 75-81, 2014.

[15] D. Dorner, S. Zaefferer, L. Lahn, and D. Raabe, "Overview of microstructure and microtexture development in grainoriented silicon steel," Journal of Magnetism and Magnetic Materials, vol. 304, no. 2, pp. 183-186, 2006.

[16] U. Yoshiyuki, M. Masato, F. Masahiro, K. Takeshi, F. Hiroyasu, and M. Kenichi, "Recent development of low-loss grainoriented silicon steel," Journal of Magnetism and Magnetic Materials, vol. 254-255, pp. 307-314, 2003.

[17] N. A. Castro, M. F. de Campos, and F. J. G. Landgraf, "Effect of deformation and annealing on the microstructure and magnetic properties of grain-oriented electrical steels," Journal of Magnetism and Magnetic Materials, vol. 304, no. 2, pp. e617e619, 2006

[18] L. Fangfang, Study on Hi-B Steel Recrystallization During the Hot Deformation Process by Thermal Simulation, Wuhan University of Science and Technology, 2015.

[19] Z. Shifeng, Study on Microstructure and Texture During Hot Rolling and Normalizing of Twin-Roll Cast, Northeastern University, 2009.

[20] Z.-L. Jin, H.-P. Ren, W. Li, and Y.-M. Li, "Effect of thermomechanical treatment history upon annealing microstructure and texture of a cold rolled nonoriented silicon steel," Transactions of Materials and Heat Treatment, vol. 33, no. 2, pp. 122-126, 2012.

[21] Y. B. Xu, Y. X. Zhang, Y. Wang et al., "Evolution of cube texture in strip-cast non-oriented silicon steels," Scripta Materialia, vol. 87, pp. 17-20, 2014. 
[22] Y. H. Sha, C. Sun, F. Zhang et al., "Strong cube recrystallization texture in silicon steel by twin-roll casting process," Acta Materialia, vol. 76, pp. 106-117, 2014. 

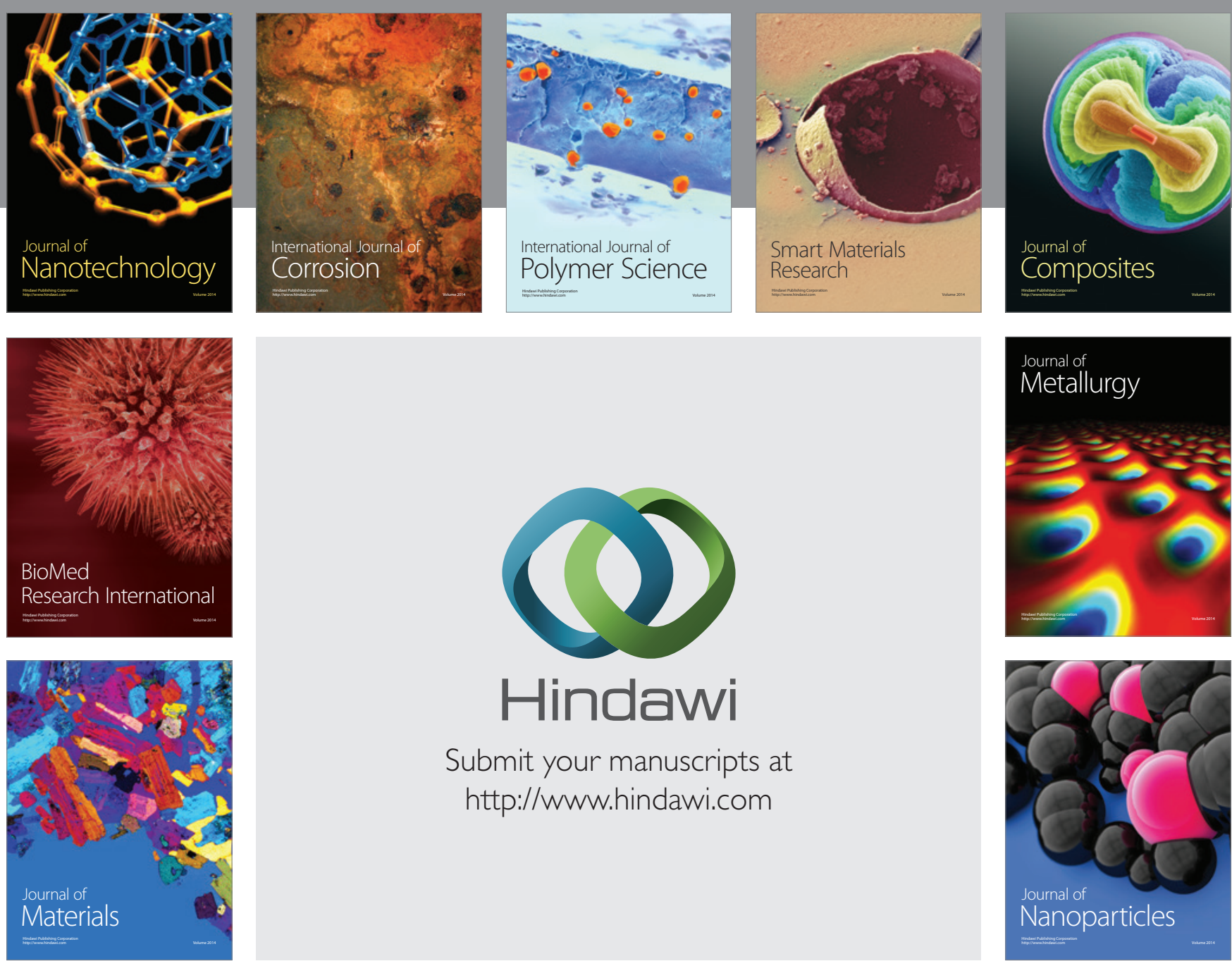

\section{Hindawi}

Submit your manuscripts at

http://www.hindawi.com

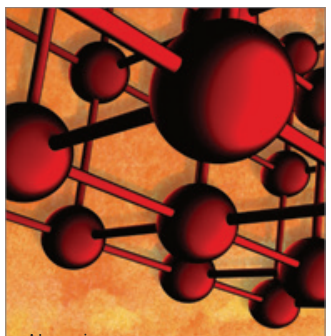

Materials Science and Engineering
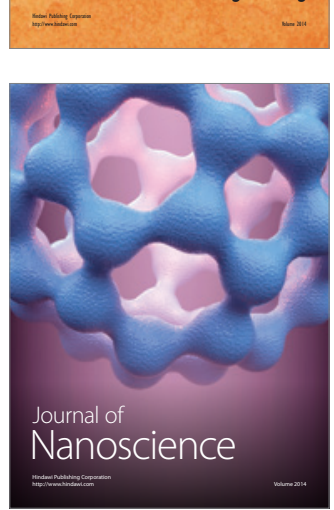
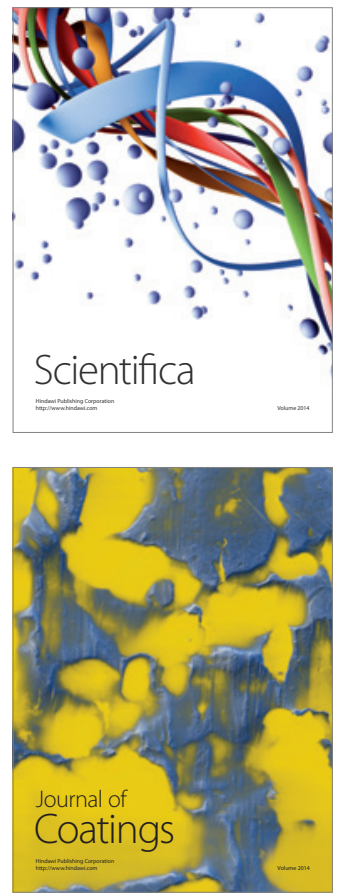
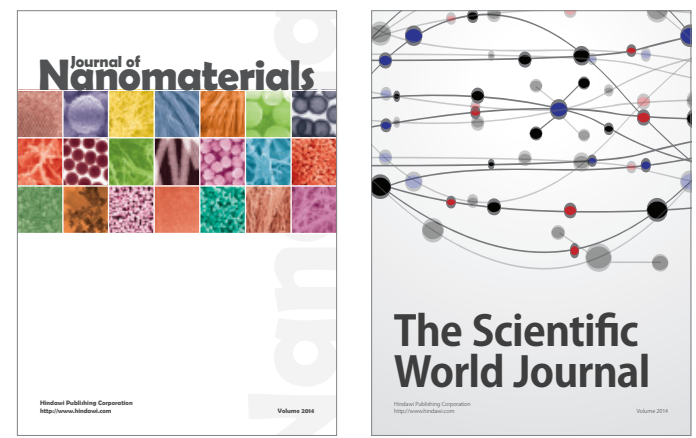

The Scientific World Journal
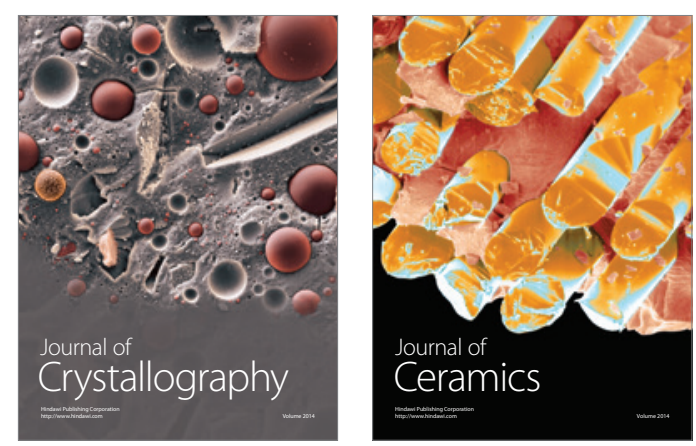
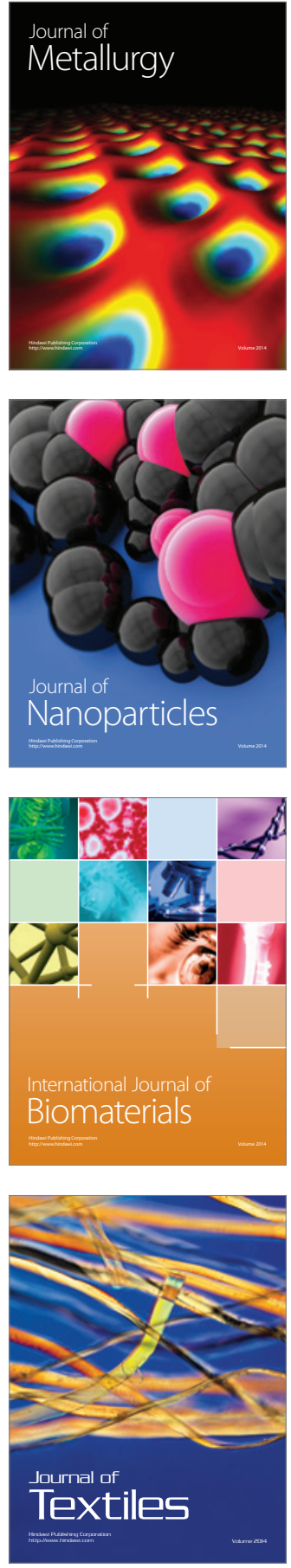